\title{
FEASIBILITY OF INTEGRATED TRANSPORT NETWORK MODEL IN LITHUANIA
}

\author{
Lina Papšienè ${ }^{1}$, Andrius Balčiūnas ${ }^{2}$, Giedrè Beconytè ${ }^{2}$, Danas Motiejauskas ${ }^{3}$, \\ Denis Romanovas ${ }^{3}$, Vladislovas Česlovas Aksamitauskass ${ }^{1}$, Kęstutis Papšys ${ }^{3}$ \\ ${ }^{1}$ Dept of Geodesy and Cadastre, Vilnius Gediminas Technical University, Vilnius, Lithuania \\ ${ }^{2}$ Centre for Cartography, Vilnius University, Vilnius, Lithuania \\ ${ }^{3}$ State Enterprise 'GIS-Centras', Vilnius, Lithuania
}

Submitted 8 September 2013; resubmitted 29 March 2014; accepted 21 April 2014

\begin{abstract}
Availability of up-to-date and detailed spatial data on transport networks is very important for sustainable development. As Directive 2007/2/EC of 14 March 2007 establishing an Infrastructure for Spatial Information in the European Community (INSPIRE) targets transport networks data as one of the first priority data themes to be harmonized across Europe, the specification for transport network dataset has been developed and adopted as guidance document for all Member States. The specification provides a common model for road, rail, air, water and cable transport networks and related infrastructure. Integrated transport network database can be used for routing of vehicles, taking into account all limitations of the road network, for transport planning, emergency services. In order to achieve the benefits related to common use of up-to-date information and to interoperable data for these tasks, all transport network elements must be accurately mapped in a consistent logical network. Unfortunately, in Lithuania there is no single continuous and extensive spatial data set (geographic database) of transport networks. The authors analysed the possibilities of building joint INSPIRE databases from different transport datasets, and indicated the best data sources for road and railway transport, as well as actions of improvement have to be taken. The research and successful experiment has showed that the more extensive INSPIRE transport data model can be implemented using ArcGIS data model. This concept and the model will serve as an important prop for development of policy of national and transboundary spatial data integration in countries with similar situation. INSPIRE implementation guidelines are compatible with national interest and must be followed, but technical feasibility and cost-benefit considerations must be taken into account.
\end{abstract}

Keywords: transport network model; harmonisation; roads; geographic data; INSPIRE.

\section{Introduction}

Directive 2007/2/EC of the European Parliament and of the Council of 14 March 2007 establishing an Infrastructure for Spatial Information in the European Community (INSPIRE) was in force in May 2007. The implementation of INSPIRE is strongly affecting the development of national Spatial Data Infrastructures (SDI). Studies on implementation of INSPIRE in European countries (Grus et al. 2011; De Vries et al. 2011) revealed that, while the most of European countries follow the designoriented policy of implementation, i.e., transpose legislation, and aim to timely comply with INSPIRE technical specifications, some others, such as the Netherlands, Sweden, Germany, uphold the systematic approach. The essence of so called cultivation approach (De Vries et al. 2011) lies in outlining the components that would com- plement the INSPIRE objectives in the long run, based on evaluation of the current situation. The authors in this paper support the latter approach and have followed it in the research on development of transport network model in Lithuania.

In order to assure interoperability of trans-boundary datasets, common data specifications have been developed and adopted as INSPIRE guidance documents. In order to ensure interoperability across spatial data themes, the EU Member States are expected to meet requirements for common data types, framework for unique identification of spatial objects, key attributes, metadata, generic network model and other rules that apply to 34 spatial data themes listed in the three Annexes to the Directive. Transport network data theme fell into the first priority list of data themes to be harmo-

Corresponding author: Lina Papšienè

E-mail: lina@rytai.lt 
nized (the themes included in Annex I of the Directive) and INSPIRE Data Specification on Transport Networks (INSPIRE 2010) has been published in 2010. This specification has been developed by expert group with participation of representatives of various organisations in Europe who have extensive knowledge and experience in this field. It is designed in a way to serve different national purposes and to provide a framework for combining transport network information from different countries into a single best dataset. Transport networks in the context of the Directive mean road, rail, air water and cable transport networks and related infrastructure, including links between different networks. INSPIRE is primarily an environmental directive, therefore the specification was developed mainly to support environmental impact assessments. At higher levels, spatial information classified as Transport theme is crucial for spatial decision making - from management and rational planning to sustainable development of the country and of the European Community (Szeto et al. 2012). No solid scenarios for spatial development can be based on fragmented and differently interpreted information on transport infrastructure. Building an integrated national transport network database is the first step towards harmonisation of data belonging to the Transport theme.

Integrated transport network database can be used for various important applications based on technologies of Geographic Information Systems (GIS), such as routing of vehicles, taking into account all limitations of the road network; transport network design, planning and maintenance (Burinskienè et al. 2011; Arampatzis et al. 2004; Jenelius 2009); flow modelling, traffic control and management (Vardi 1996; Min, Wynter 2011; Jeung et al. 2010; Crisostomi et al. 2011); incident and disaster management (Jasiūnienè et al. 2012; Taniguchi et al. 2012), emergency services, asset management, environmental impact assessment (Gulliver, Briggs 2005) and map generalisation (Touya 2010). Links between different transport networks can be used in transportation Object-Oriented GIS (Trépanier, Chapleau 2001). In order to take advantage of these possibilities in national and local public sector, all transport network elements must be accurately mapped in a consistent logical link and node network.

The key characteristics of efficient national transport network dataset, compatible with general requirements for a European SDI dataset, are as follows:

- the dataset must contain information that can be employed to support economic growth through safe, ecological and efficient transportation;

- the structure of the dataset must be stable and extensible in order to support more object types for future applications, including private sector applications;

- the structure of the dataset must efficiently support frequent updates of data;

- the transport dataset must be interoperable with other datasets of national extent and importance, such as datasets containing addresses, geographical names, hydrography etc.
Lithuania is among the first countries in the EU that have developed modern SDI and the geoportal. The Lithuanian spatial information portal accessible at $h t t p: / / w w w . g e o p o r t a l . l t$ is an efficient platform for sharing all geographic data (spatial datasets) and developing various applications. However, aggregate value of national SDIs depends not only on technology but also on available data, among which well-developed and reliable transport network plays a very important role. The team of the authors since 2009 continuously work on theoretically based methodology of INSPIRE implementation in Lithuania. We seek to introduce sustainable solutions for sharing different spatial datasets that would be efficient for national purposes in the long term. The main objectives are to develop flexible and cost-efficient data integration models and to provide practical recommendations of implementation and use. Analysis of alternatives reveals strong and weak points of use of INSPIRE data specifications in the national organisational and technological environment.

The paper discusses the possibility to develop an integrated transport network dataset that is compliant with the requirements set in the INSPIRE Data Specification on Transport Networks (INSPIRE 2010) and can be used for diverse national purposes.

\section{Availability of Spatial Data on Transport in Lithuania}

Typically, a spatial dataset of transport network encompasses spatial objects of network elements and information related to the physical characteristic of object (e.g., pavement of a road) or descriptive information of the transport system (e.g., speed limitation). Some national and foreign commercial companies develop and maintain road transport data sets or networks for their business purposes in the territory of Lithuania. They collect necessary data from various organisations, add missing elements and update the data according to a particular business-oriented plan. Most often, such networks serve the specific tasks of logistics, such as finding the nearest, quickest, optimal route etc. In Lithuania there is no single official spatial data set of roads' or entire transport system network. On the other hand, spatial data related to transport network elements are collected in several different national spatial data sets and information systems in Lithuania. They are stored at different levels of completeness and at various scales. Innovative GIS technologies enable integration of these spatial data and information from different data sources into a topologically consistent transport network. One of the tasks of the research was to analyse available national spatial data sets in Lithuania and to select the most suitable spatial data for developing transport network compatible with the requirements of INSPIRE.

According to the INSPIRE Data Specification on Transport Network (INSPIRE 2010) the main aspects for modelling the network are:

- spatial - geometric (point, line, area) representation of the network elements; 
- temporal - information about temporal validity and life-cycle of network elements; temporal information is particularly important for analytical purposes, such as discovery of complex transport flow patterns (Liu et al. 2011; Min, Wynter 2011);

- thematic - thematic information about elements of a transport network such as speed limitation, road width, restrictions etc.

Initial analysis allowed selecting the national spatial data sets that could be used for modelling transport network:

- the Cadastre of Georeference Spatial Data (GRPK) and the Georeference Spatial Data Sets at the scales of 1:10000 (GDR10LT), 1:50000 (GDR50LT) and 1:250000 (GDR250LT);

- the Georeference Spatial Data set of the territory of the Republic of Lithuania at scale 1:250000 according to the requirements of the international project EuroRegionalMap (ERM_250LT);

- the Spatial Data Sets of Lithuanian Road Information System (LAKIS).

The first two groups of selected spatial datasets collect georeference spatial data. This data represent permanent natural and anthropogenic objects of the real world. GRPK collects centre lines of all roads and railways on the territory of Lithuania. All the objects of GRPK have unique identification numbers and information about their life-cycle (i.e., the dates of object creation, update and deletion). The main data sources for creating and updating objects are newest orthophotographic images and field measurements. Therefore only several attribute important for transport network, for example, information on road width and cover, must be collected directly. On another hand, GRPK has implemented possibility to receive other attributes of roads from LAKIS and the Address Register of Lithuania. LAKIS contains information about route numbers, categories and pavements of national roads, the Address Register of Lithuania contains the names of the streets. GRPK is consistently updated. However, traffic information or spatial data of water and air transport are not stored in the GRPK.

Another set of georeference spatial data is the GDR10LT. It encompasses all the objects and attributes of the GRPK. Additionally, the territories of airports, heliport, aerodromes and runway without specific attributes of transport network are collected in the GDR10LT. This data may be used to form a part of the air transport network, although they would not be very significant in general transport network.

The updated GDR10LT (together with GRPK) is used for updating the GDR50LT, GDR250LT and ERM_250LT datasets. The GDR50LT contains the same spatial and attribute data related to transport network as of the GDR10LT and is updated every 3-4 years. More extensive thematic information is stored in the GDR250LT data set that meets the national needs and the main requirements of the EuroRegionalMap (EuroGeographics 2013). However this dataset has not been updated since 2007. Therefore these two datasets are not really suitable for developing or updating the transport network.
ERM_250LT is a possible alternative to the GDR250LT. This national data set completely corresponds to the requirements of the EuroRegionalMap. The EuroRegionalMap is a multifunctional topographic dataset covering 35 countries. One of the designations of this data set is its use in network analysis tasks. It includes spatial data and attributes of roads, railways, ferry lines, locations of airports, harbours, railway stations, parking areas, level crossings, road interchanges etc. However, the transport objects of this dataset are strongly generalised, that means, they do not always precisely represent the real locations of the objects and not all the objects are represented. Also the ERM_250LT does not include all the information specified for INSPIRE, in some cases attribute data are based on information from official data sources and all spatial data of transport network are updated only once in a few years.

The scheme in Fig. 1 represents the data sources used for updating the national georeference spatial data sets in Lithuania.

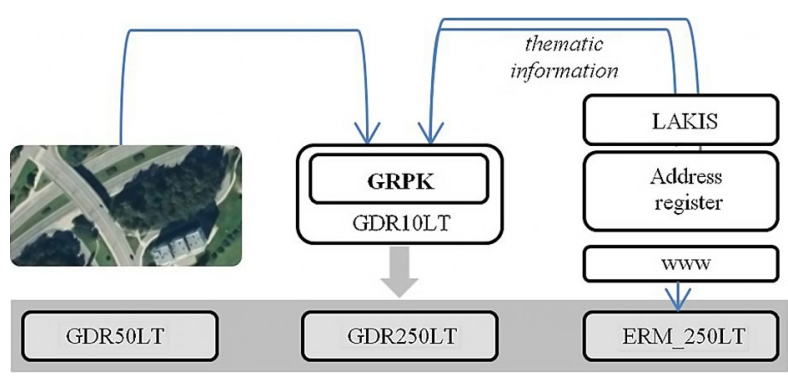

Fig. 1. The data sources for updating the national georeference spatial datasets in Lithuania

Lithuanian Road Information System (LAKIS 2014) is an information system of national roads. The main objective of the system is to store in a centralised way, manage, process, analyse, represent and present the data on road and bridge inventory, on construction of the road surface, and statistical information on traffic and bridge inspection. The LAKIS consists of two core data sets that could be used for creation of the national road network or INSPIRE Transport Network:

- the dataset describing the road infrastructure, in which inventory and statistical information of road infrastructure elements on traffic, such as parking places, bypasses, junctions and other elements is stored;

- the road network dataset used for route planning, in which information necessary for building networks (access prohibitions, border crossing points, barriers above the road and bridge inventory information) is stored.

Additionally, data are collected for tools related to choosing the most cost-effective traffic safety engineering solutions (Skrinskas 2012). But it should be noted that currently all that data were created just in part and cover solely the information on the roads of national significance (Fig. 2) and are updated once a year. 
Analysis of current situation in Lithuania shows that there is no single spatial data set that would properly represent transport system according to the requirements of INSPIRE Transport Network.

Considering the analysis of spatial data currently available at the national level, their accuracy and regularity of update, the most suitable national spatial data sets for creating national or INSPIRE Transport Network were selected (Fig. 3).

A road transport network may include spatial data from two national data sets:

- the GDR10LT that includes spatial data of all the roads (including the streets) on the territory

a)

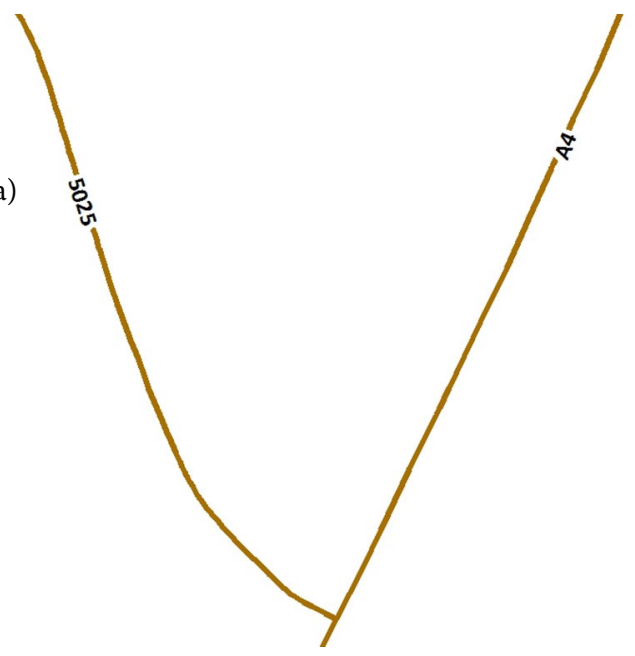

b)

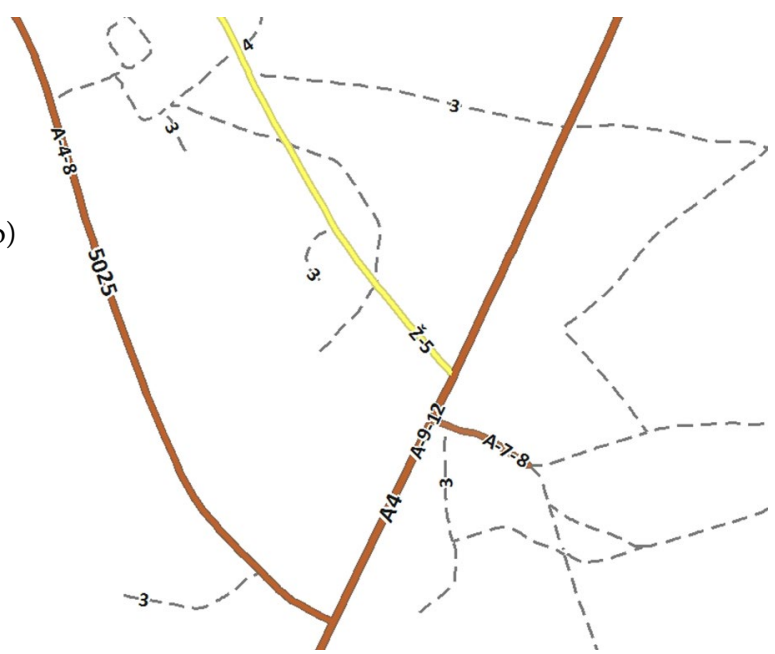

Fig. 2. The examples of spatial data of (a) national significance roads in LAKIS and (b) the roads in the GDR10LT

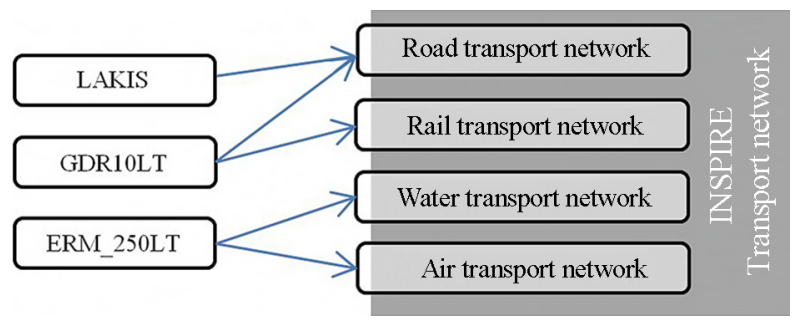

Fig. 3. Selected data sources of INSPIRE Transport Network of Lithuania, but store a comparatively small amount of thematic information requested by INSPIRE;

- the LAKIS road infrastructure and road network data sets cover all roads of national significance on the territory of Lithuania and some thematic information related to the physical characteristic and traffic.

Regarding to the available data the road transport network has to include spatial objects of national roads from the LAKIS. Other roads have to be collected from the GDR10LT. But it should be noted sometimes configuration of roads objects in GDR10LT and LAKIS are not identical or compatible to each other currently, therefore they have to be corrected.

The GDR10LT may be used for the rail transport network. As it was mentioned above, this data set contains spatial data of railways that are presently most appropriate according to the INSPIRE Data Specification on Transport Network.

It is much more difficult to ensure availability of spatial data for developing water and air transport networks due to following reasons:

- there are no consistent national datasets on water and air transport with appropriate topology;

- information from ERM_250LT is not reliable due to relatively small scale (1:250000 vs. 1:10000 of the GDR10LT and LAKIS).

Any Lithuanian spatial data set include elements of the cable transport network.

Thus there exist data from which transport network can technically be created. However, the INSPIRE Data Specification on Transport Network (INSPIRE 2010) encompasses diverse spatial and attribute data that do not exist in appropriate form in any of the national spatial data sets in Lithuania. Target national spatial data sets only cover approx. $42 \%$ of the main spatial objects (elements of transport) and $27 \%$ of attribute (thematic) information requested by INSPIRE. Relative availability of information for each type of network in Lithuania against the number of entities and attributes listed in the INSPIRE specification is shown in Fig. 4. Therefore we propose to develop the INSPIRE Transport Network in the territory of Lithuania gradually, starting with the

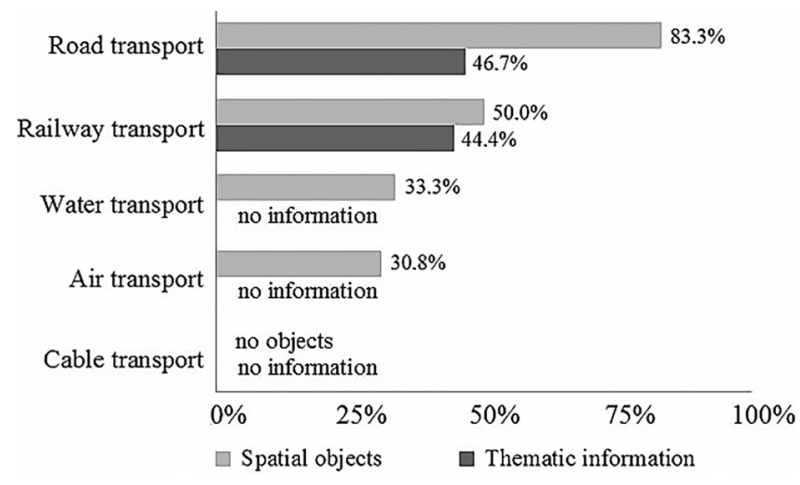

Fig. 4. Coverage of data specification on Transport Network by national spatial datasets 
model that initially includes limited amount of the specified data objects for the road, rail, water and air transport networks. In the future the model can be extended by adding more entities and/or attributes as long as they become available.

\section{Aspects of Implementation of INSPIRE Data Specification on Transport Networks}

Analysis of national spatial data sets has revealed that road transport data cover the larger part of specification of INSPIRE Transport Network with precise geometry and official approved attribute data related to transport network. Besides that, road transport plays the most important role in Lithuania. A part of rail network with precise geometry can as well be created. We have tested the restructuring of the spatial data of LAKIS and GDR10LT in order to form an INSPIREcompliant model. The transformation was realised using the Extract-Transform-Load (ETL) process. This process extracts data from outside sources, transforms it to fit operational needs, and loads it into the end database.

The testing of restructuring of selected spatial data encompassed:

- transformation of the geometry of spatial data;

- transformation of the attributes of spatial data;

- creation of additional spatial elements of INSPIRE Transport Network.

Two main problems related to the data structure were identified during transformation of geometry of spatial data.

The first problem is transformation of linear features into the link-and-node data model. Spatial road data stored in the GDR10LT accurately represent the real world objects, centrelines of roads, streets and interconnections. However, local topology restrictions are different from the INSPIRE Transport Network topology restrictions. The main problem is violation of the Requirement 10 (INSPIRE 2010) of the specification: '[...] nodes shall only be present where Transport Links connect or end'. In the reference spatial data sets all lines that intersect are split at intersection points even if in the real world such intersection does not exist (Fig. 5).

Unnecessary connections nodes may be seen (circled in red) in places of multi-level intersections. These nodes do not represent real world link connections. They should be removed to build INSPIRE conformant road network.

Thus during the process of building INSPIRE Transport Network node and link representation of plain linear data unnecessary nodes are introduced. There are no algorithms to correctly eliminate these extra nodes. Therefore formal automatic processing tools (e.g. ETL) cannot be used (Vassiliadis et al. 2002). Manual data inspection using orthophotographic imagery or even on-site inspection (if imagery is outdated) should be performed. Manual inspection of more than 300000 features is a time consuming process. Therefore data would be transformed only once, because updates would take the same amount of manual editing over and again, so it will not be efficient. The other way of tackling this a)

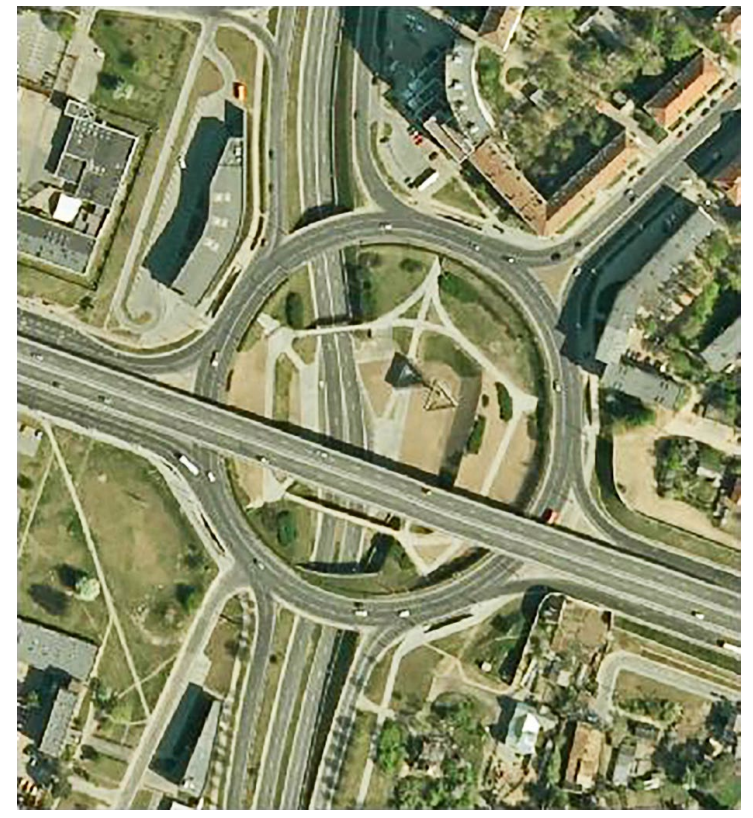

b)

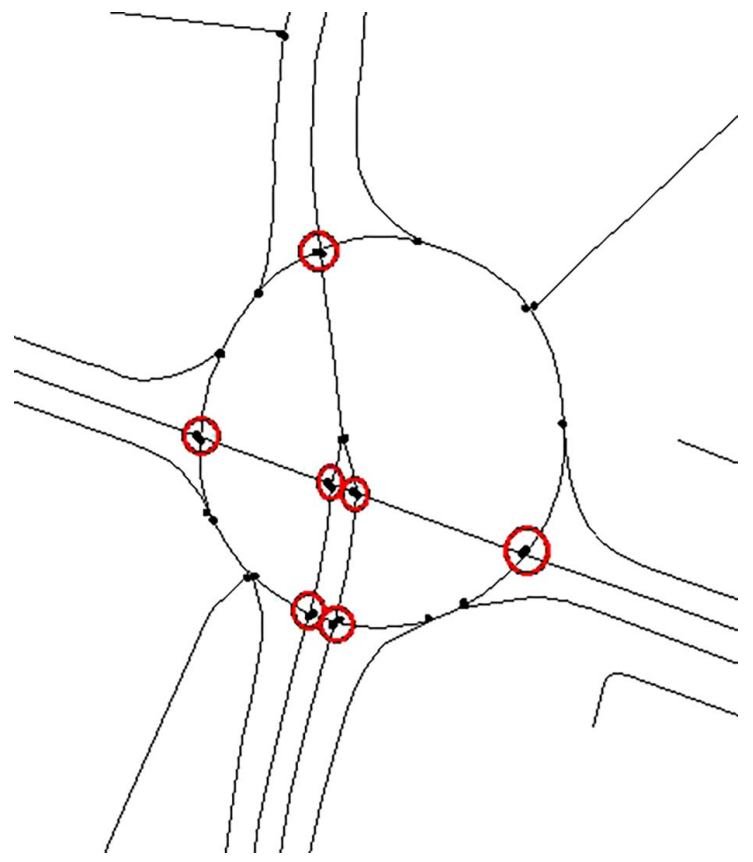

Fig. 5. A complex three-level intersection (a) is represented by line features (b)

problem is to change the specification of the national reference data so that extra nodes would not be introduced or they would be marked as overpass/underpass where applicable.

Another significant problem is related to the line directions. Link direction is the most important attribute for network routing. Although this attribute is not obligatory in application schema Road Transport Network, but its absence may result in very inaccurate or even unusable routing results. It makes sense to assume that link direction is the same as the coordinate order of a line, but it will only work for one-way roads. So there is a need for attribute or property that would indicate 
whether the line is one-way or two-ways. Such property is not stored in any of the reference datasets. Data on link direction for national roads can be found in LAKIS, but they do not cover directions of streets in cities. Again, manual data inspection and property assignment is required.

Consistency of attribute information in the national datasets is a prerequisite of successful automated data transformation. Some existing discrepancies have been successfully solved and a functional INSPIRE Transport Network containing links, nodes and areas for roads and railways was created and the elements of road network successfully mapped into ArcGIS data model for route planning as demonstrated in the next chapter.

\section{INSPIRE Road Network for Route Planning in the National SDI}

Spatial data set of transport network is used for various tasks. The most common use is route finding and planning. This task is the most important for specialised applications of transport networks in GIS desktop software or GIS solutions available via Internet including infrastructures of national SDI. Good route planning is crucial for resource flow management (logistics), business analysis, accessibility analysis and similar tasks that are often performed by means of web map applications, general (such as Google maps and Bing maps) as well as specialised (e.g., applications in spatial information portals and Web GIS). The most common questions to be answered by such applications, among others, are:

- locating closest facilities for a given location;

- finding the shortest routes between given locations;

- computation of the most efficient routes;

- defining service areas based on travel time or distance.

Route finding and planning is commonly used in emergency and rescue operations. Emergency action planning requires the most precise and comprehensive transport network data that should be timely updated and accessible without restrictions. Road network model is extensively used for these purposes, thus the National Transport Network must first of all satisfy planning and analysis needs related with roads. Implementation of INSPIRE requirements creates opportunity to develop road network model for general national purposes.

The authors tested linking of the elements of data structure defined by the INSPIRE Data Specification on Transport Networks to requirements for the roads data that originate from the best practices of route planning in SDIs.

The initial road network data structure for efficient route planning largely depends on the two factors:

- application purpose that may or may not require evaluation of temporal costs, average fuel consumption (in litres per kilometre multiplied by the distance), analysis of alternatives, optimisation and other functionality other than just computation of the shortest route;
- software that is used for implementation of the planning algorithm and for publishing applications on the web.

However, the basic structural elements (road attributes) can be defined, that do not depend on the above mentioned factors and are necessary for initial route planning functionality (Hatakeyama, Childs 2011). The Table describes the six main attributes necessary for creating a routing service.

If the above listed attribute data are collected, route planning and other network analysis tasks can be performed on the database. The INSPIRE Data Specification on Transport Networks (INSPIRE 2010) defines 16 attributes of road network data set: ERoad, FormOfWay, FunctionalRoadClass, NumberOfLanes, RoadLinkSequence, RoadName, RoadServiceArea, RoadServiceType, RoadSurfaceCategory, RoadWidth, SpeedLimit, VehicleTrafficArea, Road, RoadArea, RoadLink and RoadNode. It can be stated that this specification fully covers the six primary attributes used for routing that are sufficient for present national needs. Moreover, INSPIRE specification encompasses other attributes that are not commonly used for routing (e.g., WeatherConditionValue, RoadServiceTypeValue) but can be important for optimization of the process.

The authors tested the network model for routing service on ArcGIS software for the following reasons:

- ensuring better interoperability as ArcGIS software is used in the Lithuanian spatial information portal that will be used to provide INSPIRE compliant transport data and related services;

- it is the most commonly used GIS software in Lithuania for creating spatial datasets (e.g. GDR10LT) or routing services (e.g. LAKIS).

Tools for network-based spatial analysis have been applied. The six core attributes are implemented in the ArcGIS network model making this model easily extendable without hard coding.

The domains of attributes set by the INSPIRE specification are different from the domains required by the ArcGIS Routing service, but the values stored in two models can be transformed from INSPIRE data model automatically using ETL processes as depicted in Fig. 6.

Thus it can be stated that INSPIRE Data Specification on Transport Networks (INSPIRE 2010), as it concerns road network, is appropriate for route planning. As soon as all European Union member states shall implement and share their official transport network data, it will be possible to implement a comprehensive and efficient routing service.

The model INSPIRE network data set on roads was designed and tested for route planning (Fig. 7). It can be stated that implementation of the INSPIRE specification not only ensures that the country formally meets the requirements of the directive for the Transport theme, but it can also be used for various applications at the state level. 
Table. The main attributes for routing service

\begin{tabular}{|c|c|c|c|}
\hline Attribute & $\begin{array}{l}\text { Attribute } \\
\text { name }\end{array}$ & Description & $\begin{array}{l}\text { Available } \\
\text { from }\end{array}$ \\
\hline ONEWAY & $\begin{array}{l}\text { Road } \\
\text { direction }\end{array}$ & $\begin{array}{l}\text { The correct values of this attribute are crucial for avoiding errors in route planning. } \\
\text { Recommended domain of this attribute consists of three values: } \\
\text { FT (one-way road permitting travel only in the digitized direction of the centre line); } \\
\text { TF (one-way road permitting travel only against the digitized direction of the centre line); } \\
\text { N (road segment that does not permit travel in either direction). }\end{array}$ & LAKIS \\
\hline SPEED KMH & $\begin{array}{l}\text { Expected } \\
\text { driving } \\
\text { speed on } \\
\text { the road }\end{array}$ & $\begin{array}{l}\text { The values of this attribute can be calculated automatically if information on speed } \\
\text { limitations for the road is stored in the database or if it can be determined by the stored } \\
\text { road category and speed limitation set for this category (e.g., } 90 \mathrm{~km} / \mathrm{h} \text { for secondary } \\
\text { roads in Lithuania). However, in order to estimate the speed correctly exact data of road } \\
\text { category and of limitations for each segment of the road where speed limitations differ } \\
\text { from default limitation for the corresponding category must be stored in the database. } \\
\text { Maximal driving speed is rather a formal parameter that is applicable in ideal driving } \\
\text { conditions. Instead, statistical evaluations derived from long term observations carried } \\
\text { out in different circumstances can significantly improve reliability of speed estimation for } \\
\text { the network model. }\end{array}$ & LAKIS \\
\hline $\begin{array}{l}\text { OVERPASS/ } \\
\text { UNDERPASS }\end{array}$ & $\begin{array}{l}\text { Type } \\
\text { of road } \\
\text { intersec- } \\
\text { tion }\end{array}$ & $\begin{array}{l}\text { The values of this attribute indicate whether there is connectivity along the intersecting } \\
\text { roads or that the overlapping segments mean road crossing at different levels (a bridge } \\
\text { or overpass). Necessity of this attribute is determined by the method and data used for } \\
\text { building the network - if digitized road data do not contain adjoining lines except for the } \\
\text { real crossroads, the intersection type attribute can be dropped. }\end{array}$ & $\begin{array}{l}\text { LAKIS } \\
\text { GDR10LT }\end{array}$ \\
\hline NAME & $\begin{array}{l}\text { Road } \\
\text { name }\end{array}$ & $\begin{array}{l}\text { The name of a street or a road segment is used for compilation of informative directions to } \\
\text { the user (e.g., 'Leave from } 6 \text { Vyšnių gatvé, Pasvalys'; 'Arrive at } 4 \text { Girniūnų gatvė, Kiemeliai, } \\
\text { Pasvalys'). }\end{array}$ & GDR10LT \\
\hline ROAD CLASS & $\begin{array}{l}\text { Road } \\
\text { type }\end{array}$ & $\begin{array}{l}\text { Similarly to the name attribute, road type attribute is used in driving directions. The values } \\
\text { of this attribute may vary depending on the country and on the complexity of the road } \\
\text { network. }\end{array}$ & $\begin{array}{l}\text { LAKIS } \\
\text { GDR10LT }\end{array}$ \\
\hline HIERARCHY & $\begin{array}{l}\text { Road } \\
\text { category }\end{array}$ & $\begin{array}{l}\text { The hierarchic category of the road (Primary road, Secondary road, Local road etc.) is } \\
\text { used for optimisation of route planning, e.g., the highest hierarchical level segments are } \\
\text { first taken into account for planning the fastest route. }\end{array}$ & $\begin{array}{l}\text { LAKIS } \\
\text { GDR10LT }\end{array}$ \\
\hline
\end{tabular}

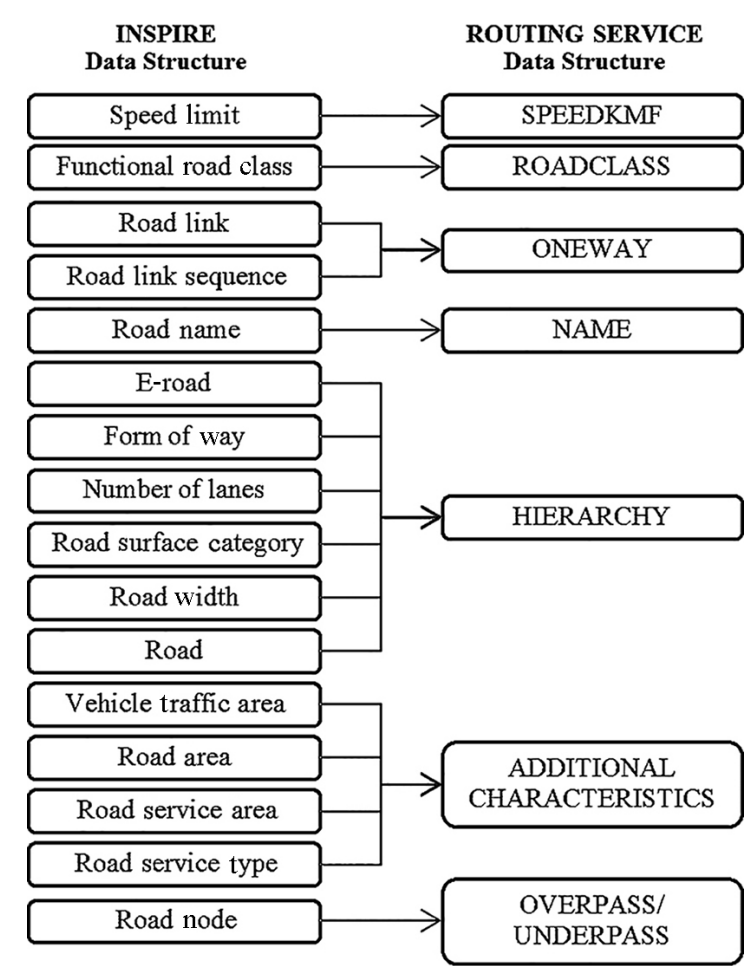

Fig. 6. Links between network dataset attributes of INSPIRE Data Specification on Transport Networks (INSPIRE 2010) and of ArcGIS Routing service

\section{Conclusions}

Implementing Rule on Interoperability of Spatial Data Sets and Services is legally binding for the Member States, but technical feasibility and cost-benefit considerations must be taken into account while following the implementation guidelines as transport networks are concerned.

Information on transport available in Lithuania as well as in many European countries is uneven, fragmented and scattered across various national and municipal datasets. There is no single national spatial data set in Lithuania that would cover all or even a significant part of information on transport implied by the INSPIRE Transport Network scheme. The most realistic approach is a spatial integration of several existing national spatial data sets of GDR10LT, LAKIS and ERM_250LT.

The spatial data sets of GDR10LT, LAKIS and ERM_250LT, cannot be used directly for developing national or the INSPIRE Transport Network, therefore conversion will be needed and additional efforts shall have to be made to eliminate existing inconsistencies in selected national spatial data set (i.e., between roads of LAKIS and GDR10LT).

The first implementation of the National Transport Network Model may include only are the most important part of transport data in Lithuania, namely, road data. 


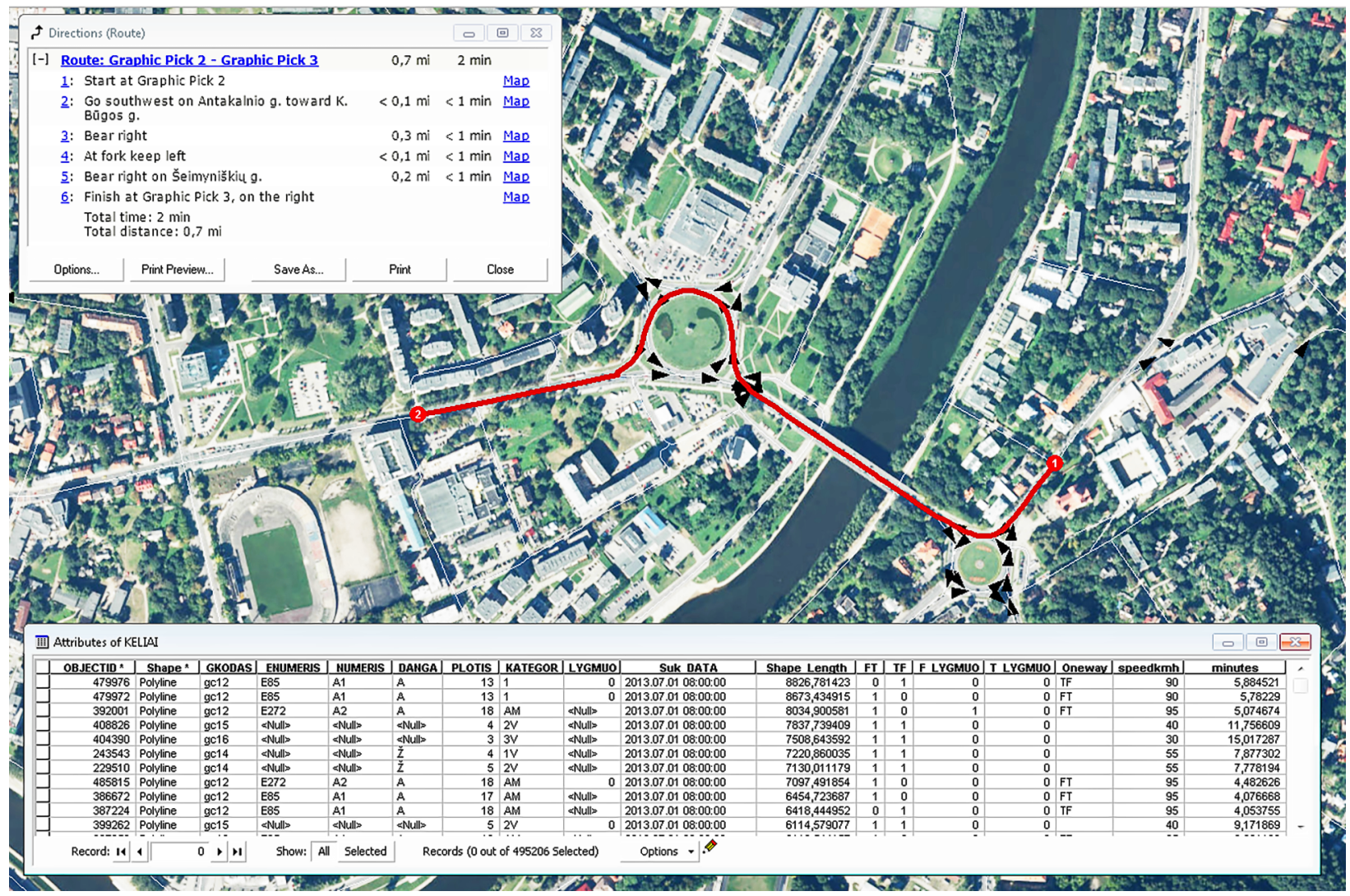

Fig. 7. Routing task performed on INSPIRE road model: geometry and textual instructions for the route between the specified points and attribute table used for routing

It was demonstrated that a conjoint road data set can be created from GDR10LT and LAKIS and supplemented by both spatial and thematic information provided in the future by other datasets maintained by municipalities, other state institutions and private companies. Such road dataset meets INSPIRE requirements and can be used for various network tasks. It has been tested with ArcGIS routing service and proved fully functional for route finding and planning.

Officially accepted common National Transport Network model and a corresponding integrated dataset made available at national spatial information portal would serve as an appropriate base for fostering extensive collection and maintenance of transport information in the primary transport data sets.

\section{Acknowledgements}

Thanks are due to State Enterprise 'GIS-Centras' and to the National Land Service under the Ministry of Agriculture of Lithuania for permission to use national reference datasets in this research.

We are grateful to the Lithuanian Road Administration for sharing the data used in the Lithuanian Road Information System.

\section{References}

Arampatzis, G.; Kiranoudis, C. T.; Scaloubacas, P.; Assimacopoulos, D. 2004. A GIS-based decision support system for planning urban transportation policies, European Journal of Operational Research 152(2): 465-475.

http://dx.doi.org/10.1016/S0377-2217(03)00037-7

Burinskienè, M.; Ušpalytė-Vitkūnienè, R.; Tuminienè, F. 2011. Public transport integration into urban planning, The Baltic Journal of Road and Bridge Engineering 6(2): 84-90. http://dx.doi.org/10.3846/bjrbe.2011.11

Crisostomi, E.; Kirkland, S.; Shorten, R. 2011. A Google-like model of road network dynamics and its application to regulation and control, International Journal of Control 84(3): 633-651. http://dx.doi.org/10.1080/00207179.2011.568005

De Vries, W. T.; Crompvoets, J.; Stoter, J.; Vanden Berghe, I. 2011. Atlas of INSPIRE - evaluating SDI development through an inventory of INSPIRE experiences of European National Mapping Agencies, International Journal of Spatial Data Infrastructures Research 6: 126-144. http://dx.doi.org/10.2902/1725-0463.2011.06.art6

Directive 2007/2/EC of the European Parliament and of the Council of 14 March 2007 Establishing an Infrastructure for Spatial Information in the European Community (INSPIRE). Available from Internet: http://eur-lex.europa.eu/legal-content/EN/ALL/?uri=OJ:L:2007:108:TOC

EuroGeographics. 2013. EuroRegionalMap v6.0. Available from Internet: http://www.eurogeographics.org/products-andservices/euroregionalmap

Grus, Ł.; Castelein, W.; Crompvoets, J.; Overduin, T.; Van Loenen, B.; Van Groenestijn, A.; Rajabifard, A.; Bregt, A. K. 2011. An assessment view to evaluate whether Spatial Data Infrastructures meet their goals, Computers, Environment and Urban Systems 35(3): 217-229.

http://dx.doi.org/10.1016/j.compenvurbsys.2010.09.004 
Gulliver, J.; Briggs, D. J. 2005. Time-space modeling of journey-time exposure to traffic-related air pollution using GIS, Environmental Research 97(1):10-25. http://dx.doi.org/10.1016/j.envres.2004.05.002

Hatakeyama, A.; Childs, C. 2011. Network Analyst: Creating Network Datasets. Presentation, in ESRI International User Conference (ESRI UC), 11-15 July 2011, San Diego, CA, USA. 49 p. Available from Internet: https://s3.amazonaws. com/webapps.esri.com/esri-proceedings/proc11/techworkshops/tw_1024.pdf

INSPIRE. 2010. D2.8.I.7 INSPIRE Data Specification on Transport Networks - Guidelines. INSPIRE Thematic Working Group Transport Networks. 203 p. Available from Internet: http://inspire.ec.europa.eu/documents/Data_Specifications/INSPIRE_DataSpecification_TN_v3.1.pdf

Jasiūnienè, V.; Čygas, D.; Ratkevičiūtè, K.; Peltola, H. 2012. Safety ranking of the Lithuanian road network of national significance, The Baltic Journal of Road and Bridge Engineering 7(2): 129-136. http://dx.doi.org/10.3846/bjrbe.2012.18

Jenelius, E. 2009. Network structure and travel patterns: explaining the geographical disparities of road network vulnerability, Journal of Transport Geography 17(3): 234-244. http://dx.doi.org/10.1016/j.jtrangeo.2008.06.002

Jeung, H.; Yiu, M. L.; Zhou, X.; Jensen, C. S. 2010. Path prediction and predictive range querying in road network databases, The VLDB Journal 19(4): 585-602. http://dx.doi.org/10.1007/s00778-010-0181-y

LAKIS. 2014. Lietuvos automobiliu keliu informacine sistema [Applications of the Lithuanian Road Information System]. Available from Internet: http://lakis.lakd.lt

Liu, W.; Zheng, Y.; Chawla, S.; Yuan, J.; Xing, X. 2011. Discovering spatio-temporal causal interactions in traffic data streams, in KDD'11: Proceedings of the 17th ACM SIGKDD International Conference on Knowledge Discovery and Data Mining, 21-24 August 2011, San Diego, CA, USA, 1010 1018. http://dx.doi.org/10.1145/2020408.2020571

Min, W.; Wynter, L. 2011. Real-time road traffic prediction with spatio-temporal correlations, Transportation Research Part C: Emerging Technologies 19(4): 606-616. http://dx.doi.org/10.1016/j.trc.2010.10.002

Skrinskas, S. 2012. International and scientific activities of the Lithuanian Road Administration are the source of experience, The Baltic Journal of Road and Bridge Engineering 7(3): 169-172. http://dx.doi.org/10.3846/bjrbe.2012.23

Szeto, W. Y.; Jaber, X; Wong, S. C. 2012. Road network equilibrium approaches to environmental sustainability, Transport Reviews 32(4): 491-518.

http://dx.doi.org/10.1080/01441647.2012.690000

Taniguchi, E.; Ferreira, F.; Nicholson, A. 2012. A conceptual road network emergency model to aid emergency preparedness and response decision-making in the context of humanitarian logistics, Procedia - Social and Behavioral Sciences 39: 307-320. http://dx.doi.org/10.1016/j.sbspro.2012.03.110

Touya, G. 2010. A road network selection process based on data enrichment and structure detection, Transactions in GIS 14(5):595-614. http://dx.doi.org/10.1111/j.1467-9671.2010.01215.x

Trépanier, M.; Chapleau, R. 2001. Linking transit operational data to road network with a transportation object-oriented GIS, URISA Journal 13(2): 23-30.
Vardi, Y. 1996. Network tomography: estimating source-destination traffic intensities from link data, Journal of the American Statistical Association 91(433): 365-377. http://dx.doi.org/10.1080/01621459.1996.10476697

Vassiliadis, P.; Simitsis, A.; Skiadopoulos, S. 2002. Conceptual modeling for ETL processes, in DOLAP'02: Proceedings of the 5th ACM international workshop on Data Warehousing and OLAP, 4-9 November 2002, McLean, VA, USA, 14-21. http://dx.doi.org/10.1145/583890.583893 